\title{
0 impacto da Lei de Responsabilidade Fiscal no desempenho financeiro e na execução orçamentária dos municípios no Rio Grande do Sul de 1997 a 2004*
}

\author{
Sandra Regina Toledo dos Santos** \\ Tiago Wickstrom Alves***
}

SumÁrio: 1. Introdução; 2. A LRF e os impactos na gestão orçamentária municipal; 3. Indicadores de desempenho para a gestão governamental; 4 . Prodecimentos metodológicos; 5. Análise dos indicadores orçamentários; 6. Conclusões.

Summary: 1. Introduction; 2. The Fiscal Responsibility Act and its impacts on municipal budget management; 3 . Government management performance indicators; 4. Methodological procedures; 5 . Analysis of budget indicators; 6. Findings.

Palavras-chave: Lei de Responsabilidade Fiscal; orçamento; finanças públicas.

KeY WORDs: Fiscal Responsibility Law; budget; public finances.

Este trabalho analisa através de indicadores os orçamentos e os dados dos balanços dos municípios do estado do Rio Grande do Sul, no período de 1997 a 2004, com objetivo de avaliar o impacto que a Lei de Responsabilidade Fiscal (LRF) teve sobre o desempenho financeiro e na execução orçamentária. Para tal avaliação, utilizou-se de um modelo de regressão, com dados em painel, e constatou-se que os resultados na expressiva maioria dos indicadores apresentaram uma melhora em seus valores após a LRF, confirmando a mudança teórica esperada.

\footnotetext{
* Artigo recebido em ago. 2007 e aceito em nov. 2009.

** Mestre em contabilidade. Professora assistente da Universidade de Passo Fundo (UPF) e funcionária da Prefeitura de Passo Fundo (RS), Assessoria Superior. Endereço: Rua Moron, 901, ap. 702 - Centro - CEP 99010-030, Passo Fundo, RS, Brasil.E-mail: sandratche@upf.br.

*** Doutor em economia. Professor titular dos mestrados de contabilidade e economia da Universidade do Vale do Rio dos Sinos (Unisinos). Endereço: Av. Unisinos, 950 - CEP 93022-000, São Leopoldo, RS, Brasil. E-mail: twa@unisinos.br.
} 
The impact of the Fiscal Responsibility Act on financial performance and budget execution in Rio Grande do Sul municipalities from 1997 to 2004

This paper analyses the performance of Rio Grande do Sul cities based on economic and financial indicators from 1997 to 2005 aiming at assessing the impact of the so-called Fiscal Responsibility Law (FRL) on financial performance and budget execution. Nine indicators were employed and through a regression using panel data it was estimated the changes on those indicators after the introduction of the FRL. The results show that seven out of the nine indicators had a better performance due to the FRL, as expected by the theory.

\section{Introdução}

A composição dos diversos interesses dos setores público e privado evidencia as diferentes necessidades e funcionalidades dos orçamentos em cada ambiente. As mudanças de estratégias e o desempenho dos níveis de gerência são refletidos nos orçamentos em termos de maior ou menor poder discricionário para os executivos, impactando o resultado das organizações.

Assim, vislumbra-se o orçamento como um instrumento gerencial que impacta e possibilita avaliar o desempenho financeiro das organizações, cujos resultados refletem as variações ocorridas no período, proporcionando uma análise acerca da condução dos planos orçamentários, elemento que dá sentido a este trabalho.

As publicações especializadas evidenciam a utilização dos orçamentos ao longo do tempo, desde o feudalismo até a atual sociedade democrática, sob o enfoque de questões que abordam o controle, a transparência e o planejamento dos recursos que são colocados à disposição das organizações. Percebese que desde o surgimento desse instrumento na área pública, a complexidade que envolve os aspectos econômicos e financeiros tem exercido forte pressão sobre os governantes, no que tange à conciliação entre as necessidades coletivas e a capacidade do governo em supri-las (Moojen, 1959; Deodato, 1965; Baleeiro, 1972; Silva, 1973; Lee e Johnson, 1977; Paysant, 1999).

As mudanças ocorridas no âmbito público, abordadas em estudos mais recentes, como os de Oag (1993); Inap (1997); Knowles, Leighton e Stinson (1997); Darmohraj e outros (2001); Bezerra Filho (2002); Campello (2003); Guzmán (2003); Solá (2003); Guimarães, Cavalcanti e Affonseca (2004), reportam-se à questão da produtividade e da qualidade dos serviços prestados como forma de torná-los mais ágeis para conter os elevados gastos que tornaram as esferas governamentais deficitárias. Os resultados financeiros negativos da União, estados e municípios, mensurados através dos balanços, tornou 
visível o novo direcionamento a ser dado à atuação dos gestores, onde a busca pela eficiência gerencial e a utilização dos recursos de forma mais adequada tornou-se a tônica da gestão pública.

Essa busca pelo controle e eficiência das ações do poder público concretiza-se, no Brasil, pelo advento da Lei de Responsabilidade Fiscal (LRF), em maio de 2000. O objetivo da LRF era introduzir métodos que possibilitassem ampliar o controle e a transparência dos atos dos gestores como: a inserção de publicações periódicas dos relatórios de gestão, o monitoramento dos índices orçamentários, o controle da despesa pública e o aumento na arrecadação da receita, forçando uma maior eficiência da gestão e a obtenção do equilíbrio das contas públicas.

Este trabalho tem como hipótese que a LRF, ao reduzir o grau de discricionariedade dos gestores nos orçamentos e aumentar a transparência das contas públicas, gerou uma melhora no desempenho financeiro dos municípios. Diante dessa hipótese, o objetivo principal está em analisar o impacto da LRF nos orçamentos e no desempenho financeiro dos municípios do estado do Rio Grande do Sul, possibilitando estabelecer um nexo entre o que se pretende com a lei e os resultados obtidos depois de decorrido um mandato municipal de adequação às regras legais estabelecidas. O conhecimento desses resultados contribuirá para avaliar o efeito da LRF e gerará informações que possibilitarão maior eficiência na elaboração de novas regulamentações referente aos orçamentos.

Este trabalho contém, além dessa introdução: revisão da literatura do impacto da LRF nos orçamentos; discussão e alguns indicadores de desempenho; descrição dos procedimentos adotados para estimar o efeito da LRF sobre o os indicadores de desempenho; análise dos resultados obtidos a partir da estimação dos parâmetros do modelo estabelecido; por fim, as conclusões.

\section{A LRF e os impactos na gestão orçamentária municipal}

A concepção do novo sistema de gestão pública, abordado pela literatura recentemente, enfatiza que a estrutura dos governos deveria passar por um processo de transformação visando a reduzir o tamanho do Estado (Osborne e Gaebler, 1997:15; Santos, 2001:2; Asazu e Abrucio, 2003:2; Sacramento, 2004:10; López, 2006:7), devido ao excesso de atribuições e ao elevado custo dos serviços prestados. Logo, esses componentes estariam comprometendo a continuidade das suas atividades e desencadeando crises financeiras sucessivas. 
Diante disso, Sacramento (2004:25-26) promove um debate acerca das dificuldades enfrentadas pelo Estado antecedente às reformas, citando fatores como: a globalização da economia, onde uma crise localizada pode influenciar o resultado de outros governos; a falta de condições para financiar os déficits acumulados ao longo do tempo; a necessidade de estabelecer métodos que permitissem o controle dos recursos públicos reforçando a questão do planejamento das ações governamentais; e, ainda, as mobilizações que ocorreram, tanto da sociedade quanto do próprio Estado, por uma maior transparência na prestação dos serviços públicos e pela busca de um equilíbrio das finanças do governo.

Nesse contexto, Asazu e Abrucio (2003:8) consideram que a busca por mudanças derivou tanto de uma "maior pressão da mídia e da opinião pública por um comportamento responsável dos governantes, em vista dos sucessivos escândalos envolvendo o erário público", como da influência do estabelecimento de normas internacionais visando ao ajuste das contas públicas dos países envolvidos no Tratado de Maastricht, o Budget Enforcement Act (BEA) dos EUA e o Fiscal Responsibility Act da Nova Zelândia.

Na América Latina, também ocorreram alterações sobre a condução dos processos orçamentários que visavam promover o equilíbrio fiscal, principalmente, por imposições do Fundo Monetário Internacional (FMI) aos países que necessitam de recursos advindos dessa fonte, conforme descrito por Nunes e Nunes (2001:229).

Segundo Asazu e Abrucio (2003:2-3), a partir de 1993 no Brasil, as reformulações financeiras no governo federal decorreram fundamentalmente das ações do então ministro da Fazenda Fernando Henrique Cardoso, que tinham como foco principal o ajuste fiscal das contas públicas e que acabaram por promover as reformas administrativas e previdenciárias no final da mesma década, já como presidente da República.

Nesse cenário, a aprovação da Lei de Responsabilidade Fiscal tornou-se iminente e foi inserida no âmbito governamental brasileiro em 5 de maio de 2000 , exigindo a adequação dos gestores aos ordenamentos preconizados em seu texto, que busca estabelecer normas de finanças públicas voltadas para a responsabilidade na gestão fiscal. Para tal, pressupõem uma ação planejada e transparente, conforme consta no art. $1^{\circ}$. Isso exigiu e exige novas competências para conduzir o gerenciamento dos órgãos públicos.

A partir de sua implantação, o planejamento das ações públicas centrase cada vez mais na importância de três "figuras" orçamentárias em busca do equilíbrio fiscal, que são: o Plano Plurianual; a Lei de Diretrizes do Orçamento; e a Lei Orçamentária Anual (Sacramento, 2004:42). 
Desde a Lei 4.320/1964, os órgãos públicos estavam obrigados a apresentar somente os anexos contidos em seu texto, a fim de evidenciar os resultados orçamentários, financeiros e patrimoniais no final do exercício. Com a LRF, foram inseridos os Anexos de Metas Fiscais, de Riscos Fiscais e o Relatório de Gestão Fiscal, para demonstrar efetivamente como as contas públicas estão sendo conduzidas e a accountability fiscal.

A LRF direciona aos municípios um "espírito inovador da gestão responsável, onde o que não se pode mais admitir é o déficit motivado pela superestimação da receita no orçamento" (Toledo Jr. e Rossi, 2001:8). Ou seja, os ajustes financeiros e orçamentários municipais sofreram um impacto mais forte do que o previsto, pois as distorções evidenciadas na elaboração da receita acabavam comprometendo o desempenho anual das finanças públicas.

Rückert, Borsatto e Rabelo (2002:25-38) evidenciaram em pesquisa realizada nos municípios gaúchos, conforme dados do período de 1995 a 1999 , os seguintes itens:

a) as transferências com o Imposto sobre Circulação de Mercadorias e Serviços e sobre Prestações de Serviço de Transporte Interestadual e Intermunicipal e de Comunicação (ICMS) registraram queda em torno de $22,4 \%$ nos municípios de 50.001 a 100.000 habitantes, e a cota-parte do Fundo de Participação dos Municípios (FPM) apresentou uma redução de 23,0\% para 20,5\% na composição geral das receitas orçamentárias municipais;

b) as receitas tributárias aumentaram 13,8\% durante o período analisado;

c) os investimentos sofreram redução de $21 \%$ durante o período, com maior reflexo nos municípios com população de 50.000 a 100.000 habitantes;

d) a capacidade de gerar poupança corrente nos municípios analisados foi negativa, isto é, a receita corrente foi inferior à despesa corrente, evidenciando aumento da dependência destas unidades com as transferências constitucionais para cobrir os gastos e realizar novos investimentos.

Diante destes resultados, percebe-se que os déficits ocorridos dificultaram a realização de investimentos públicos nos municípios gaúchos, agravando a situação financeira desses no período analisado, não obstante o aumento das receitas próprias.

No mesmo sentido, um levantamento realizado por Bremaeker (2002:1) no período de 1997 a 2000, em nível nacional, apontou que, em 1998, cerca de 55,5\% dos municípios apresentavam déficits fiscais. Aqueles com até 5.000 habitantes foram os que apresentaram os melhores resultados, embora a par- 
ticipação da receita tributária própria desses seja de até 10\% na composição dos seus orçamentos, sinalizando maior dependência financeira dos pequenos municípios das transferências constitucionais do FPM e ICMS, assemelhandose ao já constatado por Rückert, Borsatto e Rabelo (2002).

No que tange à análise da LRF, Figueiró e outros (2002:2-6) demonstraram através de pesquisa realizada nos municípios brasileiros, em 2001, que em $91 \%$ dos municípios:

a) houve geração de poupança corrente;

b) ocorreu forte dependência das transferências constitucionais do FPM e do ICMS em relação ao total da receita orçamentária;

c) a receita tributária não apresentou um aumento no seu potencial de exploração;

d) os investimentos tiveram cobertura financeira suficiente, porém, não foi verificado se houve aumento per capita;

e) a dívida fundada apresentou elevação em somente 1,1\% da amostra estudada.

Os resultados obtidos através dessas pesquisas formam um panorama das contas municipais no final da década de 1990: as despesas superavam a arrecadação, comprometimento do nível de investimentos, dependência nos repasses constitucionais do FPM e ICMS, alta incidência das despesas com pessoal em relação à receita orçamentária e endividamento ascendente.

Com a inserção da LRF, constatou-se que os municípios ainda são dependentes dos repasses constitucionais. Apesar da queda nessas arrecadações, ocorreu uma contenção do endividamento e, por fim, uma receita tributária ainda pouco explorada. Esses elementos induzem a necessidade de planejamento orçamentário a fim de obter resultados positivos e de adequação às normas estabelecidas pela LRF.

Discutida a questão da LRF e seus efeitos nas contas públicas municipais, torna-se necessário para os objetivos desse trabalho discutir indicadores que possam avaliar os resultados econômico-financeiros das contas públicas. E é deste tema que trata a seção seguinte.

\section{Indicadores de desempenho para a gestão governamental}

Essa seção tem como objetivo salientar a importância da análise de desempenho, apresentar as referências das quais foram retirados os indicadores uti- 
lizados e descrevê-los, não tendo como escopo a realização de uma ampla discussão a respeito de formas de avaliação.

No que se refere à análise de desempenho, a busca pela transparência nos órgãos públicos proporcionou mudanças em âmbito municipal. Estudos recentes apontam como destaque a accountability na responsabilização pelas ações de governo e no controle dos processos de interesse coletivo (Saldanha, 2001; Slomski, 2001; Asazu e Abrucio, 2003; Sacramento, 2004). Pode-se discorrer, ainda, sobre a divulgação de todos os resultados oriundos da execução orçamentária através dos relatórios de gestão; a apresentação das contas realizadas pelo chefe do Executivo; a aplicação dos recursos públicos conforme determinam o Plano Plurianual e a Lei de Diretrizes Orçamentárias; e posteriormente, pela inserção de nova regulamentação sobre os procedimentos de compras públicas através da modalidade Pregão, que visa diminuir os custos nos processos licitatórios, conforme a Lei 10.520/2002, reformulando, assim, a Lei de Licitações 8.666/1993.

Darmohraj e outros (2001:27) destacam que "um dos aspectos fundamentais para a análise e a evolução dos processos é a mensuração da produtividade e do desempenho da organização". Os autores descrevem que após a identificação dos parâmetros quantitativos e qualitativos, devem-se estabelecer indicadores que evidenciem se os processos estão sendo realizados de modo eficiente e se estão gerando os resultados que os clientes e a organização desejam.

No entanto, as ações orçamentárias e financeiras oriundas dos programas de governo, em muitos casos, apresentam resultados vagos devido ao fato de que as metas não são suficientemente claras, retóricas e formais (Crozier, 1996:3). Isso tem motivado o desenvolvimento de indicadores que permitam o acompanhamento e a identificação das aplicações dos recursos e dos resultados das ações governamentais.

O fato é que "tradicionalmente, os serviços públicos são descritos como não produtivos" (Mwita, 2000:19), mas quesitos importantes para essas avaliações como a implantação de centros de custos e a mensuração dos programas de governo foram técnicas recentemente introduzidas pela LRF, que até então eram ignoradas.

Encontram-se na literatura referências relevantes sobre indicadores que possibilitam evidenciar as particularidades que envolvem a efetivação das ações públicas. Essas apontam os elementos que devem estar presentes na formulação dos indicadores de desempenho como: simplicidade de seus itens, estabilidade para permitir comparações em longos períodos e sensibilidade 
para que variações pequenas sejam percebidas (Tribunal de Contas, 2000:99; Solà, 2003:8-9).

A importância desses instrumentos — onde, na gestão pública, os resultados extraídos do orçamento permitem verificar pontos sensíveis na formulação das políticas governamentais - é ressaltada por Pace, Basso e Silva (2003:39), ao afirmarem que "um bom administrador controla o desempenho dos sistemas sob sua responsabilidade com a ajuda de medidas de desempenho".

A análise do "desempenho de um administrador pode ser feita através dos critérios da eficácia e eficiência", na ótica de Julião (2004:8). A eficiência é atribuída ao modo de executar as atividades e/ou processos e a eficácia evidencia o resultado "na escolha da alternativa correta para um determinado problema, a fim de realizar as metas e objetivos da empresa", segundo o mesmo autor.

A eficácia é identificada quando se comparam os resultados reais com os previstos, independentemente dos meios utilizados. Portanto, uma atuação eficiente e eficaz se dá pela minimização dos recursos associados à maximização dos resultados, sem comprometer a qualidade e a quantidade dos serviços públicos (Oag, 1993:107; Instituto Nacional de la Administración Pública, 1997:9; Bezerra Filho, 2002:39; Campello, 2003:40; Solà, 2003:5).

Mais recentemente, os gestores municipais têm sofrido uma pressão crescente por parte da sociedade para que gerenciem com eficiência e que sejam eficazes nos resultados, dado que cada vez mais os recursos, que são escassos, são disputados para atenderem a novas necessidades. Com a municipalização de muitos serviços públicos, a exemplo da saúde, os gestores municipais têm partido em busca de arrecadação própria, de forma intensa, para dar sustentabilidade às despesas programadas, atendendo aos ordenamentos da LRF que impõem a vedação da renúncia de receitas sob pena de comprometimento da execução das despesas.

No Brasil, a avaliação da execução orçamentária governamental foi inserida pela Lei 4.320/1964, considerando a apresentação do Balanço Orçamentário, que constitui o documento aglutinador da arrecadação e dos dispêndios dos recursos públicos, avaliação esta que foi ignorada pelas administrações desde o seu estabelecimento. Porém, "o uso de indicadores no processo orçamentário começa a ganhar destaque quando a ênfase deixa de ser na função controle e passa para a gerência e, logo em seguida, no planejamento das ações governamentais" (Varela, 2004:146).

Muitos pesquisadores têm utilizado indicadores para evidenciar o desempenho das administrações públicas. Entre eles destacam-se os de Crozier (1996), Knowles, Leighton e Stinson (1997), Dalla Vecchia (1999), Kohama (2000), Lourençon (2001), Darmohraj e outros (2001), Andrade (2002), Bezerra Filho (2002), Izaac Filho (2002), Riani (2002), Rückert, Borsatto e Ra- 
belo (2002), Campello (2003), Pace, Basso e Silva (2003), Solà (2003), Guzmán (2003), Varela (2004) e López e Corrado (2005), dois quais optou-se por nove indicadores para serem utilizados neste estudo, em função de sua ampla utilização e aceitação, que são: ${ }^{1}$

- Indicador de créditos adicionais (ICA): evidencia as alterações anuais orçamentárias calculadas considerando os créditos adicionais anuais em relação ao orçamento inicial: $I C A=C A A /$ Ir Onde: $I C A=$ Indicador de créditos adicionais; $C A A=$ Créditos adicionais anuais; $O I=$ Orçamento inicial.

- Indicador da realização da receita orçamentária (IRRO): evidencia o grau de acerto do planejamento e da estimação das receitas, considerando a receita total realizada e a receita total orçada: $I R R O=R T / V_{R T O}$ Onde: $I R R O=$ Indicador da realização da receita orçamentária; $R T R=$ Receita total realizada; $R T O=$ Receita total orçada

v Indicador da execução orçamentária corrente (IEOC): evidencia a capacidade do órgão público em manter suas despesas correntes através das respectivas receitas correntes para o mesmo período: $I E O C=R C R / D C R$ Onde: $I E O C=$ Indicador da execução orçamentária corrente; $R C R=$ Receita corrente realizada; $D C R=$ Despesa corrente realizada.

- Indicador da realização da receita tributária (IRRT): evidencia a pressão tributária exercida sobre a riqueza econômica dos municípios, mensuradas através da receita tributária arrecadada em relação ao PIB (Produto interno bruto local): $I R R T=R T R /$ IIST Onde: $I R R T=$ Indicador da realização da receita tributária; $R T R=$ Receitas tributárias realizadas; $P I B l=$ Produto interno bruto local.

- Indicador de investimentos (II): identifica a capacidade de realizar investimentos em relação ao PIB local: $I I=I E X /$ PIB̉ $_{\text {Ond }}$ Onde: IEx = Investimentos executados; PIBl = PIB Local.

- Indicador de Retorno do Imposto sobre Circulação de Mercadorias e Serviços e sobre Prestações de Serviço de Transporte Interestadual e Intermunicipal e de Comunicação (IRICMS): evidencia o retorno desse tributo aos municípios em relação a sua população: $I R T M N=R R I M S / P O p$ Onde: RRICMS = Receita realizada com ICMS; Pop = População.

\footnotetext{
${ }^{1}$ Uma lista dos principais indicadores construídos/sugeridos por alguns desses autores e outros encontra-se no anexo.
} 
- Indicador do resultado primário (IRP): evidencia a capacidade de pagamento do estoque da dívida, considerando a receita não financeira em relação à despesa não financeira: $I R P=W^{\prime} F / L$ şF Onde: $R n F=$ Receita não financeira; $\mathrm{DnF}=$ Despesa não financeira.

v Indicador de operações de crédito (IOC): evidencia o montante das operações de crédito na composição das despesas de capital $-I O C=O C K / D C R$ Onde: OCR = Operações de crédito realizadas; $\mathrm{DCR}=$ Despesas de capital realizadas.

- Indicador da amortização da dívida fundada (IADF): evidencia as amortizacõoes da dívida fundada em relação às receitas correntes realizadas: $I A D F=A D F / R C R$ Onde ADF = Amortizações da dívida fundada; $\mathrm{RCR}=$ Receitas correntes realizadas.

A seção seguinte apresenta como estes indicadores foram utilizados para avaliar o efeito da Lei de Responsabilidade Fiscal.

\section{Procedimentos metodológicos}

A análise foi focada nos municípios do Rio Grande do Sul, localizado ao Sul do Brasil, no período de 1997 a 2004, abrangendo somente os municípios que não apresentaram alterações territoriais nesse ínterim. Assim, dos 496 municípios do estado do Rio Grande do Sul, existentes em 2006, os 419 que não haviam sofrido alteração em suas áreas de 1997 a 2004 é que compõem a amostra. ${ }^{2}$

A obtenção das variáveis que compõem os indicadores deu-se através dos relatórios anuais dos balanços orçamentários e dos índices econômicos dos municípios analisados, cuja base de dados consultada está disponibilizada na home page do TCE/RS e do IBGE. Para os municípios que não possuíam os resultados anuais na base de dados do TCE/RS, foi realizado contato telefônico com as respectivas divisões de Contabilidade, bem como a elaboração e o envio de formulário para a obtenção das informações necessárias ao estudo. Em seguida, foi consultada a base de dados Finanças do Brasil (Finbra) para a conferência dos valores orçamentários devolvidos. Já naqueles com inconsistências nas informações anuais, utilizaram-se as divulgadas no ano anterior.

\footnotetext{
${ }^{2} \mathrm{~A}$ lista de municípios excluídos e dos que compuseram a amostra encontra-se no anexo.
} 
Os indicadores selecionados foram analisados através da técnica de dados em painel, incluindo uma variável dummy (D) para diferenciar o período pré e pós-implantação da LRF, que entrou em vigência em maio de 2000. Formalmente o modelo é representado pela equação:

$$
I_{i j t}=\beta_{o}+\beta_{1} D_{i t}+\beta_{2} P I B_{j t}+e_{i j t}
$$

Onde:

$I_{i j t}=$ Indicador i do município j no tempo t;

$\beta_{0}, \beta_{1}$ e $\beta_{2}=$ parâmetros da função;

$D_{i t}=$ dummy que assumirá os seguintes valores:

$D=0$ para o tempo $(t) \leq$ que o ano 2000

$D=1$ para o tempo $(t)>$ que o ano 2000

$P I B_{j t}=$ PIB do município $j$ no tempo $t$ (em milhares de reais);

$e_{i j t}=$ erro do indicador $i$ no município $j$ no tempo $t$;

$i \in[1-9]$

$j \in[1-419]$

$t \in[1997-2004]$

O modelo econométrico contém a variável $D_{i t}$, cujo parâmetro estimado $\beta_{1}$ expressará a variação no valor de cada indicador nos municípios analisados em consequência da implementação da LRF, cujos efeitos teóricos esperados são:

VICA: $\beta_{1}<0$, devido à maior adequação do planejamento orçamentário;

V IRRO: $\beta_{1}>0$, em função da arrecadação mais efetiva com a implantação da LRF;

- IEOC: $\beta_{1}>0$, devido aos mecanismos inseridos pela LRF para incrementar as receitas correntes;

- IRRT: $\beta_{1}>0$, em decorrência das restrições com a renúncia de receita e a busca pela eficiência nessa fonte de receita;

v II: $\beta_{1}<0$, em razão da diminuição nas despesas com investimentos dado o contingenciamento dos limites da dívida a longo prazo (empréstimos), para suprir essas despesas;

- IRICMS: $\beta_{1}>0$, em decorrência de uma maior efetivação na arrecadação com ICMS;

VIRP: $\beta_{1}>0$, devido à redução das despesas não financeiras;

IOC: $\beta_{1}<0$, devido à necessidade de redução de empréstimos e financiamentos; 
- IADF: $\beta_{1}<0$, devido à redução no resultado do IOC.

O PIB municipal foi utilizado como uma variável de controle para evitar erros de especificação, uma vez que muitos dos indicadores são altamente correlacionados com o mesmo.

\section{Análise dos indicadores orçamentários}

Uma vez obtidos os dados necessários para a elaboração dos indicadores e realizados os cálculos desses para a série de anos e municípios estabelecidos, estimaram-se as regressões para cada indicador conforme o modelo descrito na equação (1). Essas regressões evidenciaram mudanças significativas no parâmetro $\beta_{1}$ da dummy Dit, conforme pode ser observado na tabela 1 , que resume os resultados encontrados.

Observando os resultados apresentados na tabela 1, percebe-se que, no caso do ICA, o $\beta_{1}$, após a implantação da LRF, apresentou uma elevação de 0,013 . Ou seja, ocorreu uma ampliação da utilização de créditos adicionais após a implementação da LRF, gerando um aumento médio de 3,9\% no valor desse indicador. Como existe uma relação inversa entre o ICA e o PIB, isso poderia indicar dificuldades dos municípios mais pobres em projetar adequadamente a alocação dos recursos públicos diante de gastos na realização das políticas públicas assumidas. Destaca-se que o valor esperado era $\beta_{1}<0$, ou seja, que a LRF deveria conduzir a uma menor utilização de créditos adicionais. Porém, o que se observou foi o oposto, um acréscimo nos resultados do ICA após a LRF.

Tabela 1

Resultados da regressão dos indicadores orçamentários nos municípios gaúchos, no período de 1997 a 2004

\begin{tabular}{|lcccl|}
\hline Indicador & \multicolumn{3}{c|}{ Parâmetros estimados } & $\boldsymbol{\beta}_{\text {l }}$ de acordo com o sinal esperado \\
\hline & $\boldsymbol{\beta}_{0}$ & $\boldsymbol{\beta}_{1}$ & $\boldsymbol{\beta}_{2}$ & \\
\hline ICA & 0,308 & 0,013 & $-4,329$ & Não \\
DP & 0,003 & 0,004 & 2,12 & \\
P & 0,000 & 0,000 & 0,04 & \\
IRRO & 0,971 & 0,083 & 1,541 & Sim \\
DP & 0,003 & 0,005 & 2,38 & \\
\hline
\end{tabular}

Continua 


\begin{tabular}{|c|c|c|c|c|}
\hline \multirow[t]{2}{*}{ Indicador } & \multicolumn{3}{|c|}{ Parâmetros estimados } & \multirow[t]{2}{*}{$\boldsymbol{\beta}_{l}$ de acordo com o sinal esperado } \\
\hline & $\boldsymbol{\beta}_{0}$ & $\boldsymbol{\beta}_{1}$ & $\boldsymbol{\beta}_{2}$ & \\
\hline$P$ & 0,000 & 0,000 & 0,517 & \\
\hline IEOC & 1,145 & 0,117 & $-4,151$ & Sim \\
\hline Dp & 0,003 & 0,004 & 1,87 & \\
\hline$P$ & 0,000 & 0,000 & 0,026 & \\
\hline IRRT & 0,26 & 0,182 & 7,273 & $\operatorname{Sim}$ \\
\hline Dp & 0,016 & 0,022 & 1,06 & \\
\hline$P$ & 0,000 & 0,000 & 0,000 & \\
\hline II & 0,687 & 0,207 & $-9,796$ & Não \\
\hline Dp & 0,015 & 0,021 & 1,01 & \\
\hline P & 0,000 & 0,000 & 0,000 & \\
\hline IRICMS & 142,2 & 108,55 & 9,55 & Sim \\
\hline Dp & 3,492 & 4,856 & 2,3 & \\
\hline$P$ & 0,000 & 0,000 & 0,000 & \\
\hline IRP & 0,995 & 0,055 & 2,948 & Sim \\
\hline Dp & 0,002 & 0,003 & 1,26 & \\
\hline$P$ & 0,000 & 0,000 & 0,81 & \\
\hline $10 C$ & 0,076 & $-0,048$ & 1,11 & Sim \\
\hline Dp & 0,004 & 0,004 & $-2,1$ & \\
\hline$P$ & 0,000 & 0,000 & 0,000 & \\
\hline IADF & 2,42 & $-0,12$ & 9,05 & Sim, porém não significativo \\
\hline Dp & 0,06 & 0,08 & 3,67 & \\
\hline $\mathrm{P}$ & 0,000 & 0,17 & 0,01 & \\
\hline
\end{tabular}

Fonte: Dados do TCE/RS e IBGE.

Sendo: $D p=$ Desvio-padrão; $P=$ Nível de significância exato (" $p$ " valor).

$\mathrm{Na}$ análise do IRRO, o $\beta_{1}$ evidencia que após 2000 ocorreu uma elevação desse indicador em 0,083 . Isso significa um incremento médio na receita orçamentária em torno de $8 \%$ no período posterior à lei, que pode ser atribuído à arrecadação mais efetiva, que ocorreu, basicamente, nos tributos locais. O valor esperado para o $\beta_{1}$ era maior que zero, sendo confirmado pelos resultados do IRRO após a LRF, indicando que em relação à previsão constante nos orçamentos, a receita realizada foi acima do que vinha ocorrendo até então. Poder-se-ia esperar que municípios maiores tivessem melhores condições para ampliarem a receita, porém o $\beta_{2}$ não foi significativo, embora seu valor tenha sido positivo. 
Quanto ao IEOC, o $\beta_{1}$ obtido indica uma elevação de 0,117 no resultado do indicador nos municípios gaúchos com a implantação da LRF. Esse índice representa aproximadamente $9 \%$ de incremento na geração de poupança corrente, podendo ser relacionado aos resultados crescentes das receitas locais e da contenção dos gastos do mesmo grupo. Como o valor esperado para o $\beta_{1}$ era positivo, tem-se que os resultados confirmam essa expectativa. Assim, a LRF estimulou a maior geração da poupança corrente em nível municipal e o impacto dessa se deu de forma mais intensa nos municípios pequenos em termos de Produto Interno Bruto, uma vez que à medida que o PIB municipal aumenta o IEOC diminui. Cabe destacar que um aumento no superávit corrente proporciona aos municípios melhores condições para os pagamentos das dívidas contratadas, melhorando o perfil de gastos no futuro.

$\mathrm{Na}$ análise do IRRT, o $\beta_{1}$ obtido indica que a LRF estimulou um incremento de 0,182 no valor médio desse indicador. Atribui-se essa alteração às imposições constantes na LRF, no sentido de combater a evasão ou sonegação fiscal e de restringir a renúncia de receita que acabam ampliando a eficiência na arrecadação dos tributos. Esse resultado era esperado do ponto de vista teórico, mas é interessante observar que o IRRT apresenta valores mais expressivos nos municípios maiores. Isso indica que a taxa de crescimento das receitas tributárias é maior que a taxa de crescimento do PIB, ou seja, a receita é elástica em relação ao PIB municipal.

No que tange ao II, o $\beta_{1}$ evidencia um aumento de 0,207 após a implantação da LRF, ou seja, um incremento em torno de $30 \%$ de um período em relação ao outro. Esse crescimento, além de elevado, ocorreu em sentido contrário ao esperado. Como o PIB está negativamente correlacionado com esse indicador, mostra que as maiores dificuldades em realizar investimentos para atender as demandas sociais da população ocorreram nos municípios gaúchos menos desenvolvidos economicamente. Estes resultados crescentes podem ser atribuídos ao fato de os ajuste nos gastos das contas públicas serem mais efetivos nos municípios mais desenvolvidos economicamente; enquanto que aqueles em situação econômica oposta constituem-se em pequenas unidades de governo em que as despesas com investimentos são mais representativas em seus orçamentos.

Analisando o $\beta_{1}$ do IRICMS verifica-se que a introdução da LRF elevou de forma substancial esse indicador, ou seja, quase duplicando o valor do indicador no período 2001-2004 em relação ao de 1997-2000. Como esperado, o PIB é positivamente correlacionado com o IRICMS e foi para esse indicador o que apresentou maior sensibilidade $\left(\beta_{2}\right.$ de 9,55$)$. 
No que se refere ao resultado primário (IRP), verificu-se que a LRF permitiu um aumento da capacidade de pagamento da dívida dos municípios, pois o IRP apresentou um incremento de 0,055. Isso decorreu basicamente da intensificação do superávit primário nos municípios gaúchos.

Como aumentou o superávit primário e dado às limitações de endividamento imposta pela LRF, era esperado que ocorresse uma redução das operações de crédito. Esse resultado também foi confirmado pela regressão do IOC, demonstrado no valor de $\beta_{1}$ de - 0,048. Essa alteração representa em torno de $62 \%$ a menos de operações de crédito nos municípios do estado, essa sendo maior nos municípios menores.

Finalizando, tem-se que, em relação à amortização da dívida fundada, ocorreu uma fraca redução dessa, porém não sendo significativa do ponto de vista estatístico. Na regressão do IADF, o $\beta_{1}$ foi de - 0,12 , porém seu nível de significância foi de 0,17 , de forma que não se pode rejeitar a hipótese nula de que seu valor não é diferente de zero ao nível de significância de 10\%. Interessante observar é a sensibilidade desse indicador em relação ao PIB, que também foi um dos mais elevados $\left(\beta_{1}=9,05\right)$. Isso indica que municípios mais ricos são capazes de amortizar mais intensamente suas dívidas. Em consonância com a LRF, a partir da redução dos estoques da dívida, o resultado do indicador representa a utilização da receita total realizada em menor quantia para quitar amortizações.

\section{Conclusões}

A utilização dos orçamentos como forma de estabelecer metas a serem cumpridas pelos gestores nos órgãos públicos ganhou novo delineamento com a implantação da LRF. A lei estabelece procedimentos que visam proporcionar uma ampliação do controle dos recursos arrecadados e desembolsados para o atendimento das demandas públicas. Da mesma forma no que se refere a transparência; ou seja, foi delineada uma série de novos relatórios que buscam demonstrar mais claramente os resultados orçamentários e financeiros, bem como do planejamento dos recursos públicos.

Assim, realizou-se este estudo com o objetivo de avaliar o impacto da LRF nos municípios gaúchos em termos de desempenho financeiro e orçamentário. O que se verificou foi que ocorreu uma melhora em praticamente todos os indicadores analisados, corroborando os resultados esperados do ponto de vista teórico. 
Ou seja, aumentou a eficiência do planejamento e execução das receitas e despesas municipais evidenciado pelo aumento da capacidade de pagamento das dívidas, do equilíbrio do superávit primário e do aumento das receitas tributárias.

No entanto, dois indicadores não refletiram o valor esperado, que foram o de créditos adicionais (ICA) e o de investimentos (II). De forma que o planejamento governamental, no que se refere à capacidade de previsão de receitas, ainda não é realizado conforme as necessidades reais de cada município, de forma que ocorreu uma ampliação da utilização de créditos adicionais após a LRF. Um dos fatores que pode ter colaborado para esse resultado é justamente a tentativa dos gestores de restringir despesas para se ajustar à lei, sem que isso, de fato, seja possível no decorrer do período de execução do orçamento.

O segundo indicador que não apresentou o resultado esperado foi o de investimentos. Tinha-se como hipótese de que devido às necessidades de contingenciamento e das dificuldades impostas ao endividamento de longo prazo, o indicador de investimentos II deveria se reduzir no período pós-LRF. No entanto, ocorreu uma ampliação dos investimentos. Sendo esse resultado altamente positivo, pois possibilita maior capacidade produtiva local quando da maturação dos investimentos.

Conclui-se, dessa forma, que ao reduzir a discricionariedade dos orçamentos, a LRF foi determinante para promover os melhores desempenhos na gestão financeira dos municípios gaúchos, em geral. As contribuições vindas com a lei foram no sentido de enfatizar o controle dos recursos nas esferas governamentais, tornando-as mais eficientes, otimizando seus resultados e equilibrando as contas públicas em âmbito municipal.

\section{Referências}

ANDRADE, Nilton de Aquino. Contabilidade pública na gestão municipal. São Paulo: Atlas, 2002.

ASAZU, Cláudia Y.; ABRUCIO, Fernando L. A gênese da Lei de Responsabilidade Fiscal (LRF): a construção de uma agenda. São Paulo: Atibaia/Enanpad, 2003. CD-ROM.

BALEEIRO, Aliomar. Uma introdução à ciência das finanças. 8. ed. Rio de Janeiro: Forense, 1972.

BERGUE, Sandro Trescastro. Sistemas de planejamento e controle interno e análise de desempenho baseada em indicadores de eficácia: a proposição de uma abordagem 
da despesa pública em educação focada no programa de ensino fundamental no município de Cerro Grande do Sul. $1^{\text {a }}$ parte, agosto de 2001. Disponível em <www. federativo.bndes.gov.br/f_estudo1578.pdf>. Acesso em: 20 jan. 2006.

BEZERRA FILHO, João Eudes. Modelo conceitual de decisão e apuração de resultados: uma contribuição para avaliação da eficiência e eficácia na gestão dos recursos públicos. 2002. Dissertação (mestrado em administração) — Curso de Pós-Graduação em Administração, Universidade de São Paulo, São Paulo, 2002.

BRASIL. Lei 4320/64 de 17 de março de 1964. Disponível em: <www.tce.rs.gov. br/legislacao > . Acesso em: 13 abr. 2005.

. Lei de Responsabilidade Fiscal: Lei Complementar 101 de 4 de maio de 2000. Porto Alegre: Cartilha do Tribunal de Contas do Estado do Rio Grande do Sul, 2002.

BREMAEKER, François E.J. Panorama das finanças municipais no período de 1997 a 2000. Série estudos especiais, Rio de Janeiro, n. 36, jan. 2002. Disponível em: $<$ http://federativo.bnds.gov.br/f_estudo0001775.pdf $>$. Acesso em: 20 maio 2005.

CAMPELLO, Carlos Alberto G.B. Eficiência municipal: um estudo no estado de São Paulo. Tese (doutorado) - Programa de Pós-Graduação em Administração, Universidade de São Paulo, São Paulo, 2003.

COHEN, Ernesto; FRANCO, Rolando. Avaliação de projetos sociais. 6. ed, Petrópolis: Vozes, 2004.

CROZIER, Michael. La transación del paradigma burocrático e una cultura de gestión pública. In: CONGRESSO INTERAMERICANO DEL CLAD SOBRE A REFORMA DEL ESTADO Y DE LA ADMINISTRACIÓN PÚBLICA, 1996, Rio de Janeiro. CD - ROM.

DALLA VECCHIA. Elói. Orçamento municipal: o caso dos municípios do Planalto Médio do Estado do Rio Grande do Sul - 1989 a 1997. Dissertação (mestrado em administração) — Curso de Pós-Graduação em Administração, Universidade Federal de Santa Catarina, Florianópolis, 1999.

DARMOHRAJ, Adrian et al. Nuevas tecnologías de información en el sector público. Argentina: Instituto Nacional de Administración Pública (Inap), mar. 2001.

DEODATO, Alberto. Manual de ciência das finanças. 9. ed. São Paulo: Saraiva, 1965.

FIGUEIRÓ, Ricardo et al. Municípios: os bons resultados orçamentários se repetem em 2001. Informe-se BNDES, AFE, n. 49, dez. 2002. Disponível em: <www.bndes. gov.br/conhecimento/informeSF/inf_49>. Acesso em: 4 abr. 2006. 
GUIANET — Guia Internet Brazil. Disponível em: <www.guianet.com.br/guiacidades/>. Acesso em: jul. 2007.

GUIMARÃES, Tomás de Aquino; CAVALCANTI, Gustavo Henrique; AFFONSECA, Maria Dulce Valença de. Gestão da qualidade e inovações gerenciais em organizações públicas. Curitiba: Enanpad, 2004. CD - ROM.

GUZMÁN, Cristina Aibar. El logro del value for money en la gestión pública: consideraciones en torno a los indicadores de eficiencia, eficacia y economía. Revista Contabilidade \& Finanças, São Paulo, n. 32, p. 99-110, maio/ago. 2003.

INSTITUTO NACIONAL DE LA ADMINISTRACIÓN PÚBLICA (INAP). Evaluación en la gestión pública: conceptualización, modalidades y nuevas perspectivas. Buenos Aires, 1997.

IZAAC FILHO, Neder Renato. Construção de indicadores da execução orçamentária para a gestão pública do estado de São Paulo. Salvador: Enanpad, 2002. CD-ROM.

JULIÃO, Anderson. Avaliação de desempenho na visão da controladoria. Revista Contexto, ed. 5, 2004. Disponível em: <www.ufrgs.br/ necon/3\%20Avalia\%C3\%A7\%C3\%A3o\%20de\%20desempenho\%20-\%20Anderso n\%20Juli\%C3\%A3o.pdf>. Acesso em: 12 set. 2005.

KNOWLES, James; LEIGHTON, Charlotte; STINSON, Wayne. Indicadores de medición del desempeño del Sistema de Salud. Sep. 1997. Disponível em: <www.proadess. cict.fiocruz.br/artigos/medidas.pdf>. Acesso em: 15 jan. 2006.

KOHAMA, Héilio. Balanços públicos, teoria e prática. 2. ed. São Paulo: Atlas, 2000.

LEE, Robert D.; JOHNSON, Ronald W. Public budgeting systems. 2. ed. Baltimore: University Park Press, 1977.

LÓPEZ, Andrea. La nueva gestión pública: algunas precisiones para su abordaje conceptual. Buenos Aires: Instituto Nacional de la Administración Pública (INAP), Jun. 2006.

LÓPEZ, Andrea; CORRADO, Aníbal. Indicadores de gestión para el monitoreo de las políticas de modernización en el sector público: revisión teórica y propuesta para su elaboración. Buenos Aires: Instituto Nacional de la Administración Pública (INAP), Jun. 2005.

LOURENÇON, Cândido. O orçamento municipal como elo de ligação entre o planejamento operacional e as finanças. Dissertação (mestrado em engenharia da produção) - Curso de Pós-Graduação em Engenharia de Produção, Universidade Federal de 
Santa Catarina, Florianópolis, 2001.

MOOJEN, Guilherme. Orçamento público: estudo teórico e prático dos orçamentos estaduais do Brasil e da América do Norte. Rio de Janeiro: Financeiras, 1959.

MWITA, John Isaac. A systems-based approach to public service quality. The International Journal of Public Sector Management, v. 13, n. 1, p. 19-37, 2000. Disponível em: <www.emerald-library.com>. Acesso em: 18 jul. 2005.

NICB/UFSC. Nucleo dos Indicadores Contábeis Brasileiros. ICBs. Indicadores de análide do desempenho municipal. UFSC, 2005. Disponivel em: <www.nicb.ufsc. br>. Acesso em: 28 maio 2006.

. Indicadores de análide do desempenho municipal. UFSC, 2006. Disponivel em: <www.nicb.ufsc.br>. Acesso em: 28 maio 2006.

NUNES, Selene Peres; NUNES, Ricardo da Costa. Instituições orçamentárias: uma agenda para reformas pós Lei de Responsabilidade Fiscal. Finanças Públicas, V Prêmio do tesouro nacional, Coletânea de monografias. Brasília: Ministério da Fazenda/ Secretaria do Tesouro Nacional, 2001.

OFFICE OF THE AUDITOR GENERAL OF CANADA (OAG). Auditing of efficiency: audit guide - parte I. Trad. Curso de Frances Le Lyceé. 1. ed. Salvador: Tribunal de Contas do Estado da Bahia, 1993.

OSBORNE, David; GAEBLER Ted. Reinventando o governo. 9. ed. Brasília: MH Comunicações, 1997.

PACE, Eduardo S.U.; BASSO, Leonardo F.; SILVA, Marcos A. Indicadores de desempenho como direcionadores de valor. RAC, v. 7, n. 1, p. 37-65, jan./mar. 2003. Disponível em: <www.eac.fea.usp.br/congressousp/seminario2/trabalhos/C92. pdf $>$. Acesso em: 20 out. 2005.

PAYSANT, André. Finances publiques. 5. ed. Paris: Armand Colin, 1999.

RIANI, Flávio. Economia do setor público: uma abordagem introdutória. 4. ed. São Paulo: Atlas, 2002.

RUCKERT, Isabel Noemia; BORSATTO, Maria Luiza; RABELO, Mercedes. As finanças municipais e os gastos sociais no Rio Grande do Sul - 1995-99. Porto Alegre: Fundação de Economia e Estatística Siegfried Emanuel Heuser, 2002. (Documentos FEE; n. 50).

SACRAMENTO, Ana Rita Silva. Contribuições da Lei de Responsabilidade Fiscal para o avanço da accountability no Brasil. Curitiba: Enanpad, 2004. CD-ROM.

SALDANHA, Clézio. E como fica a questão do controle dos serviços públicos no novo gerencialismo? Campinas: Enanpad, 2001. CD-ROM. 
SANTOS, Aristeu Jorge dos. Orçamento público e os municípios: alguns conceitos de orçamento e suas repercussões na administração pública municipal. $E d$. 22, v. 7, n. 4, jul./ago. 2001. Disponível em: <http://read.adm.ufrgs.br/edicoes/dowload.php?cod_artigo $=166 \&$ cod_edicao $=18 \&$ autor $=$ Aristeu $>$. Acesso em: 20 abr. 2005.

SILVA, José Afonso da. Orçamento-programa no Brasil. São Paulo: Revista dos Tribunais, 1973.

SLOMSKI, Valmor. Manual de contabilidade pública: um enfoque na contabilidade municipal. São Paulo: Atlas, 2001.

SOLÀ, Josep Maria Guinart. Indicadores de gestión para las entidades públicas. CONGRESO INTERNACIONAL DEL CLAD SOBRE LA REFORMA DEL ESTADO Y DE LA ADMINISTRACIÓN PÚBLICA, VIII, 2003, Panamá. Disponível em: <www. unpan.xunxorg/intradoc/groups/public/documents/clad1clad0047601.pdf $>$. Acesso em: 22 dez. 2005.

TOLEDO Jr., Flávio C. de; ROSSI, Sergio Ciqueira. O processo orçamentário municipal à vista da Lei de Responsabilidade Fiscal. Revista do Direito Administrativo, n. 224, p. 169-182, jan./jul. 2001. Disponível em: < http://federativo.bnds.gov. br/bf_bancos/estudos/e0001296.pdf>. Acesso em: 20 maio 2005.

TRIBUNAL DE CONTAS. Manual de auditoria governamental. Bahia, set. 2000. Disponível em: <www.tce.ba.gov.br/tceweb/modulos/paginas/manuais/manual_auditoria.pdf >. Acesso em: 9 set. 2005.

VARELA, Patrícia Siqueira. Indicadores sociais no processo orçamentário do setor público municipal de saúde: um estudo de caso. Dissertação (mestrado em ciências contábeis) - Curso de Pós- Graduação em Ciências Contábeis, Universidade de São Paulo, São Paulo, 2004. 


\section{Anexo}

Tabela A 1

Municípios do estado do Rio Grande do Sul existentes em 2006

\begin{tabular}{|c|c|c|}
\hline \multicolumn{3}{|c|}{ MUNICÍPIOS } \\
\hline Aceguá * & Bozano * & Cidreira \\
\hline Água Santa * & Braga & Ciríaco \\
\hline Agudo & Brochier & Colinas \\
\hline Ajuricaba & Butiá & Colorado \\
\hline Alecrim & Caçapava do Sul & Condor \\
\hline Alegrete & Cacequi & Constantina * \\
\hline Alegria & Cachoeira do Sul & Coqueiro Baixo * \\
\hline Almirante Tamandaré do Sul * & Cachoeirinha & Coqueiros do Sul \\
\hline Alpestre & Cacique Doble & Coronel Barros \\
\hline Alto Alegre & Caibaté * & Coronel Bicaco \\
\hline Alto Feliz & Caiçara & Coronel Pilar* \\
\hline Alvorada & Camaquã & Cotiporã \\
\hline Amaral Ferrador & Camargo & Coxilha \\
\hline Ametista do Sul & Cambará do Sul & Crissiumal \\
\hline André da Rocha & Campestre da Serra & Cristal \\
\hline Anta Gorda & Campina das Missões & Cristal do Sul \\
\hline Antônio Prado & Campinas do Sul * & Cruz Alta * \\
\hline Arambaré & Campo Bom & Cruzaltense * \\
\hline Araricá & Campo Novo & Cruzeiro do Sul \\
\hline Aratiba & Campos Borges & David Canabarro \\
\hline Arroio do Meio & Candelária & Derrubadas \\
\hline Arroio do Padre * & Cândido Godói & Dezesseis de Novembro \\
\hline Arroio do Sal & Candiota & Dilermando de Aguiar \\
\hline Arroio do Tigre & Canela & Dois Irmãos \\
\hline Arroio dos Ratos & Canguçu & Dois Irmãos das Missões \\
\hline Arroio Grande & Canoas & Dois Lajeados \\
\hline Arvorezinha & Canudos do Vale * & Dom Feliciano \\
\hline Augusto Pestana * & Capão Bonito do Sul * & Dom Pedrito \\
\hline Áurea & Capão da Canoa & Dom Pedro de Alcântara \\
\hline Bagé * & Capão do Cipó * & Dona Francisca \\
\hline
\end{tabular}




\begin{tabular}{|c|c|c|}
\hline \multicolumn{3}{|c|}{ MUNICÍPIOS } \\
\hline Balneário Pinhal & Capão do Leão & Doutor Maurício Cardoso \\
\hline Barão & Capela de Santana & Doutor Ricardo \\
\hline Barão de Cotegipe * & Capitão & Eldorado do Sul \\
\hline Barão do Triunfo & Capivari do Sul & Encantado \\
\hline Barra do Guarita & Caraá & Encruzilhada do Sul \\
\hline Barra do Quaraí & Carazinho * & Engenho Velho \\
\hline Barra do Ribeiro & Carlos Barbosa & Entre Rios do Sul \\
\hline Barra do Rio Azul & Carlos Gomes & Entre-ljuís \\
\hline Barra Funda & Casca & Erebango \\
\hline Barracão & Caseiros * & Erechim * \\
\hline Barros Cassal & Catuípe & Ernestina * \\
\hline Benjamin Constant do Sul & Caxias do Sul & Erval Grande \\
\hline Bento Gonçalves & Centenário & Erval Seco \\
\hline Boa Vista das Missões & Cerrito & Esmeralda * \\
\hline Boa Vista do Buricá & Cerro Branco & Esperança do Sul \\
\hline Boa Vista do Cadeado * & Cerro Grande & Espumoso * \\
\hline Boa Vista do Incra * & Cerro Grande do Sul & Estação \\
\hline Boa Vista do Sul & Cerro Largo & Estância Velha \\
\hline Bom Jesus & Chapada & Esteio \\
\hline Bom Princípio & Charqueadas & Estrela \\
\hline Bom Progresso & Charrua & Estrela Velha \\
\hline Bom Retiro do Sul & Chiapeta & Eugênio de Castro \\
\hline Boqueirão do Leão & Chuí & Fagundes Varela \\
\hline Bossoroca & Chuvisca & Farroupilha \\
\hline Faxinal do Soturno & Jaguari & Nova Ramada \\
\hline Faxinalzinho & Jaquirana & Nova Roma do Sul \\
\hline Fazenda Vilanova & Jari & Nova Santa Rita \\
\hline Feliz & Joia & Novo Barreiro \\
\hline Flores da Cunha & Júlio de Castilhos & Novo Cabrais \\
\hline Floriano Peixoto & Lagoa Bonita do Sul * & Novo Hamburgo \\
\hline Fontoura Xavier & Lagoa dos Três Cantos & Novo Machado \\
\hline Formigueiro & Lagoa Vermelha * & Novo Tiradentes \\
\hline Forquetinha * & Lagoão & Novo Xingu * \\
\hline Fortaleza dos Valos * & Lajeado * & Osório \\
\hline Frederico Westphalen & Lajeado do Bugre & Paim Filho \\
\hline
\end{tabular}




\begin{tabular}{|c|c|c|}
\hline \multicolumn{3}{|c|}{ MUNICÍPIOS } \\
\hline Garibaldi * & Lavras do Sul & Palmares do Sul \\
\hline Garruchos & Liberato Salzano & Palmeira das Missões \\
\hline Gaurama & Lindolfo Collor & Palmitinho \\
\hline General Câmara & Linha Nova & Panambi \\
\hline Gentil & Maçambará & Pantano Grande \\
\hline Getúlio Vargas & Machadinho & Paraí \\
\hline Giruá & Mampituba & Paraíso do Sul \\
\hline Glorinha & Manoel Viana & Pareci Novo \\
\hline Gramado & Maquiné & Parobé \\
\hline Gramado dos Loureiros & Maratá * & Passa Sete \\
\hline Gramado Xavier & Marau & Passo do Sobrado \\
\hline Gravataí & Marcelino Ramos & Passo Fundo \\
\hline Guabiju & Mariana Pimentel & Paulo Bento * \\
\hline Guaíba & Mariano Moro & Paverama \\
\hline Guaporé & Marques de Souza & Pedras Altas * \\
\hline Guarani das Missões & Mata & Pedro Osório \\
\hline Harmonia & Mato Castelhano & Pejuçara \\
\hline Herval * & Mato Leitão & Pelotas \\
\hline Herveiras & Mato Queimado * & Picada Café * \\
\hline Horizontina & Maximiliano de Almeida & Pinhal \\
\hline Hulha Negra & Minas do Leão & Pinhal da Serra * \\
\hline Humaitá & Miraguaí & Pinhal Grande \\
\hline Ibarama & Montauri & Pinheirinho do Vale \\
\hline Ibiaçá * & Monte Alegre dos Campos & Pinheiro Machado * \\
\hline Ibiraiaras & Monte Belo do Sul & Pirapó \\
\hline Ibirapuitã & Montenegro * & Piratini \\
\hline Ibirubá & Mormaço & Planalto \\
\hline Igrejinha & Morrinhos do Sul & Poço das Antas \\
\hline ljuí * & Morro Redondo & Pontão \\
\hline Ilópolis & Morro Reuter & Ponte Preta * \\
\hline Imbé & Mostardas & Portão \\
\hline Imigrante * & Muçum & Porto Alegre \\
\hline Independência & Muitos Capões & Porto Lucena \\
\hline Inhacorá & Muliterno & Porto Mauá \\
\hline Ipê & Não-Me-Toque & Porto Vera Cruz \\
\hline
\end{tabular}




\begin{tabular}{|c|c|c|}
\hline \multicolumn{3}{|c|}{ MUNICÍPIOS } \\
\hline Ipiranga do Sul & Nicolau Vergueiro & Porto Xavier \\
\hline Iraí & Nonoai & Pouso Novo \\
\hline Itaara & Nova Alvorada & Presidente Lucena \\
\hline Itacurubi & Nova Araçá & Progresso * \\
\hline Itapuca & Nova Bassano & Protásio Alves \\
\hline Itaqui & Nova Boa Vista & Putinga \\
\hline Itati * & Nova Bréscia * & Quaraí \\
\hline Itatiba do Sul & Nova Candelária & Quatro Irmãos * \\
\hline Ivorá & Nova Esperança do Sul & Quevedos \\
\hline Ivoti & Nova Hartz & Quinze de Novembro \\
\hline Jaboticaba & Nova Pádua & Redentora \\
\hline Jacuizinho * & Nova Palma & Relvado * \\
\hline Jacutinga * & Nova Petrópolis & Restinga Seca \\
\hline Jaguarão & Nova Prata & Rio dos Índios \\
\hline Rio Grande & São Martinho da Serra & Tucunduva \\
\hline Rio Pardo & São Miguel das Missões * & Tunas \\
\hline Riozinho & São Nicolau & Tupanci do Sul \\
\hline Roca Sales * & São Paulo das Missões & Tupanciretã * \\
\hline Rodeio Bonito & São Pedro da Serra & Tupandi \\
\hline Rolador * & São Pedro das Missões * & Tuparendi \\
\hline Rolante & São Pedro do Butiá & Turuçu \\
\hline Ronda Alta & São Pedro do Sul & Ubiretama \\
\hline Rondinha & São Sebastião do Caí & União da Serra \\
\hline Roque Gonzales & São Sepé & Unistalda \\
\hline Rosário do Sul & São Valentim & Uruguaiana \\
\hline Sagrada Família & São Valentim do Sul & Vacaria \\
\hline Saldanha Marinho & São Valério do Sul & Vale do Sol \\
\hline Salto do Jacuí * & São Vendelino & Vale Real \\
\hline Salvador das Missões & São Vicente do Sul & Vale Verde \\
\hline Salvador do Sul * & Sapiranga & Vanini \\
\hline Sananduva & Sapucaia do Sul & Venâncio Aires \\
\hline Santa Bárbara do Sul & Sarandi & Vera Cruz \\
\hline Santa Cecília do Sul * & Seberi & Veranópolis \\
\hline Santa Clara do Sul & Sede Nova & Vespasiano Correa \\
\hline Santa Cruz do Sul & Segredo & Viadutos \\
\hline
\end{tabular}




\begin{tabular}{|c|c|c|}
\hline \multicolumn{3}{|c|}{ MUNICÍPIOS } \\
\hline Santa Margarida do Sul * & Selbach & Viamão \\
\hline Santa Maria & Senador Salgado Filho & Vicente Dutra \\
\hline Santa Maria do Herval & Sentinela do Sul & Victor Graeff* \\
\hline Santa Rosa & Serafina Corrêa & Vila Flores \\
\hline Santa Tereza & Sério & Vila Lângaro \\
\hline Santa Vitória do Palmar & Sertão & Vila Maria \\
\hline Santana da Boa Vista & Sertão Santana & Vila Nova do Sul \\
\hline Santana do Livramento & Sete de Setembro & Vista Alegre \\
\hline Santiago * & Severiano de Almeida & Vista Alegre do Prata \\
\hline Santo Ângelo & Silveira Martins & Vista Gaúcha \\
\hline Santo Antônio da Patrulha & Sinimbu & Vitória das Missões \\
\hline Santo Antônio das Missões & Sobradinho* & Westfalia * \\
\hline Santo Antônio do Palma & Soledade & Xangri-lá \\
\hline Santo Antônio do Planalto & Tabaí & \\
\hline Santo Augusto & Tapejara * & \\
\hline Santo Cristo & Tapera & \\
\hline Santo Expedito do Sul & Tapes & \\
\hline São Borja & Taquara & \\
\hline São Domingos do Sul & Taquari & \\
\hline São Francisco de Assis & Taquaruçu do Sul & \\
\hline São Francisco de Paula & Tavares & \\
\hline São Gabriel * & Tenente Portela & \\
\hline São Jerônimo & Terra de Areia * & \\
\hline São João da Urtiga & Teutônia * & \\
\hline São João do Polêsine & Tio Hugo * & \\
\hline São Jorge & Tiradentes do Sul & \\
\hline São José das Missões & Toropi & \\
\hline São José do Herval & Torres & \\
\hline São José do Hortêncio & Tramandaí & \\
\hline São José do Inhacorá & Travesseiro & \\
\hline São José do Norte & Três Arroios & \\
\hline São José do Ouro & Três Cachoeiras & \\
\hline São José do Sul * & Três Coroas & \\
\hline São José dos Ausentes & Três de Maio & \\
\hline São Leopoldo & Três Forquilhas & \\
\hline
\end{tabular}




\begin{tabular}{|ll|}
\hline & \multicolumn{1}{c|}{ MUNICÍPIOS } \\
\hline São Lourenço do Sul & Três Palmeiras \\
São Luiz Gonzaga * & Três Passos \\
São Marcos & Trindade do Sul \\
São Martinho & Triunfo \\
\hline
\end{tabular}

Tabela A2

\section{Listagem dos indicadores de desempenho mais utilizados na literatura}

\begin{tabular}{|c|c|c|}
\hline Nome do indicador & Equação & Autores \\
\hline \multirow[t]{3}{*}{$\begin{array}{l}\text { Indicador da execução } \\
\text { orçamentária }\end{array}$} & $100-0 \%$ & $\begin{array}{l}\text { Kohama (2000), } \\
\text { Lourençon (2001) e } \\
\text { Andrade (2002) }\end{array}$ \\
\hline & $E O=$ & Riani (2002) \\
\hline & $5 \mathrm{E}-$ & Riani (2002) \\
\hline \multirow[t]{3}{*}{$\begin{array}{l}\text { Indicador de execução } \\
\text { acumulado }\end{array}$} & $E A-6$ & Izaac Filho (2002) \\
\hline & $E A-L /$ & Izaac Filho (2002) \\
\hline & $\mathrm{EA}-\mathrm{P} /$ & Izaac Filho (2002) \\
\hline \multirow[t]{3}{*}{ Indicador de execução no tempo } & $\mathrm{ET}-\sin / \mathrm{s}$ & Izaac Filho (2002) \\
\hline & Eт $=\operatorname{Ly} / \mathrm{d}$ & Izaac Filho (2002) \\
\hline & $\mathrm{ET}-\mathrm{P}$ YKX & Izaac Filho (2002) \\
\hline $\begin{array}{l}\text { Indicador da execução } \\
\text { orçamentária corrente }\end{array}$ & $E \propto-\theta$ & $\begin{array}{l}\text { Campello (2003), } \\
\text { Ruckert, Borsatto e } \\
\text { Rabelo (2002). }\end{array}$ \\
\hline $\begin{array}{l}\text { Quociente execução } \\
\text { orçamentária }\end{array}$ & $\omega \infty-\infty O / \infty \phi$ & Kohama (2000) \\
\hline $\begin{array}{l}\text { Índice de comportamento da } \\
\text { arrecadação }\end{array}$ & $a-20 y \infty$ & Andrade (2002) \\
\hline Acerto nas receitas & $18-00 / 60 p$ & Campello (2003) \\
\hline
\end{tabular}




\begin{tabular}{|c|c|c|}
\hline Nome do indicador & Equação & Autores \\
\hline $\begin{array}{l}\text { Indicador da execução } \\
\text { orçamentária }\end{array}$ & $E O-\left(B_{0}-\theta\right)-\left(D_{0}-\theta\right)$ & Lourençon (2001) \\
\hline Indicador da receita realizada & RR- $9 /$ populosoo & $\begin{array}{l}\text { Knowles, Leighton } \\
\text { e Stinson (1997); } \\
\text { Ruckert, Borsatto e } \\
\text { Rabelo (2002). }\end{array}$ \\
\hline Indicador receita FPM & RFPH - EPPHy/ Populocos & $\begin{array}{l}\text { Ruckert, Borsatto e } \\
\text { Rabelo (2002). }\end{array}$ \\
\hline Indicador de transferências & $\pi-m$ & $\begin{array}{l}\text { López e Corrado } \\
\text { (2005) }\end{array}$ \\
\hline $\begin{array}{l}\text { Indicador de retorno do Fundo } \\
\text { de Participação dos Municípios }\end{array}$ & RFPH- ESPPH/607 & A autora \\
\hline $\begin{array}{l}\text { Indicador do Imposto sobre } \\
\text { Circulação de Mercadorias }\end{array}$ & ICis - & Riani (2002) \\
\hline $\begin{array}{l}\text { Indicador do Imposto sobre } \\
\text { Circulação de Mercadorias }\end{array}$ & ICH- बGY/populono & NICB/UFSC (2005) \\
\hline $\begin{array}{l}\text { Indicador de retorno do Imposto } \\
\text { sobre Circulação de Mercadorias }\end{array}$ & RIGN-DSCH/627 & $\begin{array}{l}\text { Ruckert, Borsatto e } \\
\text { Rabelo (2002) }\end{array}$ \\
\hline Indicador da Receita Tributária & $R 7=R 71 \%$ populono & Riani (2002) \\
\hline Indicador da Receita Tributária & 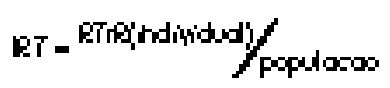 & Campello (2003) \\
\hline Indicador da Receita Tributária & $R T=R$ & $\begin{array}{l}\text { Ruckert, Borsatto e } \\
\text { Rabelo (2002) }\end{array}$ \\
\hline $\begin{array}{l}\text { Indicador da realização da } \\
\text { Receita Tributária }\end{array}$ & $1098-5$ & $\begin{array}{l}\text { López e Corrado } \\
\text { (2005) }\end{array}$ \\
\hline Indicador da Dívida Fundada & $D Q D F$ & $\begin{array}{l}\text { López e Corrado } \\
\text { (2005) }\end{array}$ \\
\hline Quociente da Dívida Fundada & $\cos =\infty / 6 \Omega$ & Kohama (2000) \\
\hline Quociente da Dívida Fundada & $\omega r-\infty \%$ & Kohama (2000) \\
\hline Indicador da Dívida Fundada & $D F-\infty \%$ & Riani (2002) \\
\hline Indicador da Dívida Fundada & $D r=\infty \sigma_{T}$ & $\begin{array}{l}\text { Riani (2002), } \\
\text { Andrade (2002) }\end{array}$ \\
\hline Indicador da Dívida Fundada & $D E=D /$ populono & $\begin{array}{l}\text { Ruckert, Borsatto e } \\
\text { Rabelo (2002) }\end{array}$ \\
\hline
\end{tabular}




\begin{tabular}{|c|c|c|}
\hline Nome do indicador & Equação & Autores \\
\hline Indicador de investimentos & $1-10$ & Riani (2002) \\
\hline Indicador de investimentos & $1-0$ & $\begin{array}{l}\text { Ruckert, Borsatto e } \\
\text { Rabelo (2002) }\end{array}$ \\
\hline Indicador de investimentos & $1-0$ & $\begin{array}{l}\text { López e Corrado } \\
\text { (2005) }\end{array}$ \\
\hline Indicador de investimentos & 1 - IE & NIBC/UFSC (2006) \\
\hline Indicador de créditos adicionais & $\alpha$ & A autora \\
\hline $\begin{array}{l}\text { Indicador de utilização de } \\
\text { créditos adicionais }\end{array}$ & $y_{x x}$ & Dalla Vecchia (1999) \\
\hline $\begin{array}{l}\text { Indicador de utilização de } \\
\text { créditos adicionais }\end{array}$ & 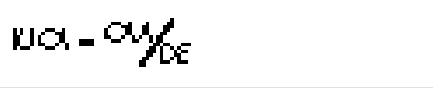 & Dalla Vecchia (1999) \\
\hline $\begin{array}{l}\text { Indicador de desenvolvimento } \\
\text { econômico-orçamentário }\end{array}$ & \%a & A autora \\
\hline $\begin{array}{l}\text { Indicador de desempenho } \\
\text { econômico-tributário }\end{array}$ & $D E T=P+1 C H /$ Fris & Datagerais (2006) \\
\hline $\begin{array}{l}\text { Indicador de transferências } \\
\text { constitucionais }\end{array}$ & $\pi c-7 \%$ / & NICB/UFSC (2006) \\
\hline \multirow[t]{2}{*}{$\begin{array}{l}\text { Indicador de eficiência dos } \\
\text { programas governamentais }\end{array}$} & 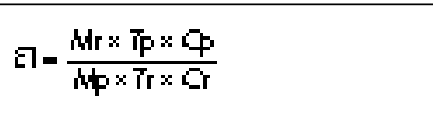 & $\begin{array}{l}\text { Orozco (1981) apud } \\
\text { Tribunal de Contas } \\
(2000)\end{array}$ \\
\hline & ถ⿻ $2 \frac{\rho p}{\sigma}$ & $\begin{array}{l}\text { Cohen e Franco } \\
(2004: 104) \text { e Varela } \\
(2004: 153)\end{array}$ \\
\hline \multirow[t]{3}{*}{$\begin{array}{l}\text { Indicadores de eficácia } \\
\text { governamental }\end{array}$} & $22=\frac{\mathrm{wr} \times T_{\mathrm{p}}}{\mathrm{w} \mathrm{p}_{\mathrm{p}} \times \mathrm{Tr}_{\mathrm{r}}}$ & $\begin{array}{l}\text { Orozco (1981) apud } \\
\text { Tribunal de Contas } \\
(2000)\end{array}$ \\
\hline & $22=\frac{L \times T_{p}}{d \times T_{r}}$ & $\begin{array}{l}\text { Cohen e Franco } \\
(2004: 102) \text { e Varela } \\
(2004: 152)\end{array}$ \\
\hline & $k=1-[(k n+i n \times \lambda 8) /$ & Bergue (2001) \\
\hline
\end{tabular}

Fonte: Construção própria. 